九州大学学術情報リポジトリ

Kyushu University Institutional Repository

\title{
A comparison of the Standing Wave and Two Microphone Methods in Measuring The Sound Absorption Coefficient of Wood
}

Kang, Chunwon

Iksan Nat i onal College, Korea

Matsumura, Junj i

Faculty of Agriculture, Kyushu Unviersity

Oda, Kazuyuki

Faculty of Agriculture, Kyushu Unviersity

https://doi.org/10.5109/4701

出版情報：九州大学大学院農学研究院紀要. 51 (1)，pp. 1-4，2006-02-01. Faculty of Agriculture， Kyushu University

バージョン:

権利関係: 


\title{
A Comparison of the Standing Wave and Two Microphone Methods in Measuring The Sound Absorption Coefficient of Wood
}

\author{
Chunwon KANG*1, Junji MATSUMURA and Kazuyuki ODA \\ Laboratory of Wood Science, Department of Forest and Forest Product Science, \\ Faculty of Agriculture, Kyushu University, Fukuoka 812-8581, Japan \\ (Received October 4, 2005 and accepted November 16, 2005)
}

\begin{abstract}
To compare the standing wave method with two microphone transfer function method in the measuring the sound absorption properties of wood, we measured the sound absorption coefficients of beech wood experimentally in the frequency range of 50 to $1600 \mathrm{~Hz}$ by the standing wave method and two-microphone method.

The sound absorption coefficient under a continuous frequency range can be estimated in a shorter time by the two microphone transfer function method than the standing wave method. There was almost no difference in measuring the sound absorption coefficients of beech wood at the estimated frequency range using both methods. The sound absorption coefficient of beech wood was a little higher than those of other construction materials.
\end{abstract}

\section{INTRODUCTION}

Wood had been used as a construction material because of good hardness, resistance to weathering, good appearance and elastic properties. In construction fields, however, proper acoustic characteristics such as sound absorption coefficient, transmission loss and normal acoustic impedance of a component are necessary to design a structure successfully.

Two commonly used methods in measuring the normal incident sound absorption characteristics of materials are the standing wave ratio method and the two microphone method. The second method was used by many researchers for the sound absorption coefficient and acoustical impedance measurement (Seybert and Ross, 1977 : Chung and Blaser, 1980 : Suzuki et al, 1981 : Katz, 2000 : Boonen and Sas, 2004).

Haines and James (1989) reported that an excellent agreement was obtained between standing wave method and two microphone method. Seybert and Ross (1977) reported that the two microphone method is about 40 times faster than the standing wave method in the measurement of normal incident sound absorption coefficients of materials. Also, Seybert and Ross (1977) suggested that great care is needed in mounting the sample on the impedance tube because of the possibility of error by the gap between the tube and sample specimen.

In this study, we measured the sound absorption coefficients of beech wood (Fagus grandifolia) by the standing wave method and two microphone transfer function method.

\section{MATERIALS AND METHODS}

\section{sample specimens}

The sample specimens used in this study were tan-

\footnotetext{
${ }^{1}$ Department of Forest Products, Iksan National College, Iksan 570-752, Korea

* Corresponding author (E-mail: kcwon@iksan.ac.kr)
}

gential-radial disks of beech wood which were prepared by mill cutting. The mean value of air-dry specific gravity, the diameter of sample specimen and moisture content were $0.76,99.6 \mathrm{~mm}$ and about $13 \%$, respectively.

\section{Standing wave method}

This method uses an impedance tube which consists of an excitation source on one end and the unknown impedance at the other end as shown in Fig. 1. The excitation source generates a sinusoidal signal which was generated from function generator and amplified by a power amplifier and which results to a standing wave pattern in the tube. The standing wave formed by the combination of incident wave and reflected wave in the tube holding a sample specimen are to be measured The traversing condenser microphone estimates the minimum and maximum pressure of the standing wave in the impedance tube. From the ratio of the minimum and maximum pressure of the standing wave, the sound absorption coefficient was calculated.

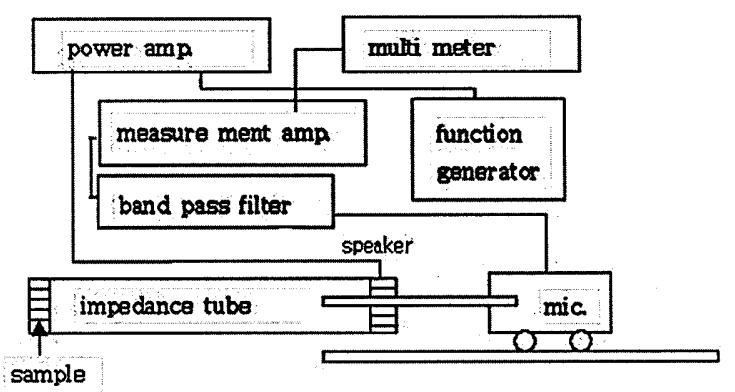

Fig. 1. Schematic diagram of the test apparatus for the stan ding wave method of measuring of sound absorption coefficient.

\section{Two microphone method}

The two microphone method is shown schematically in Fig. 2. The set-up consists of a straight tube. On one end, an excitation source-a loudspeaker was connected. 


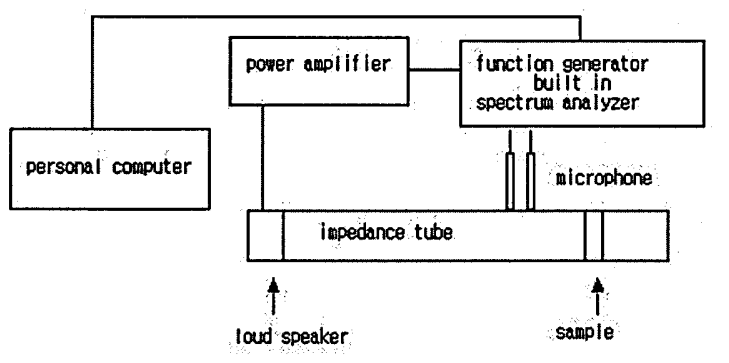

Fig. 2. Schematic diagram of the test apparatus for the two microphone method of measuring of sound absorption coefficient.

In the tube, a broadband random wave was formed by the signal generator amplified by a power amplifier and then induced to the loudspeaker. On the other end, the sound absorption coefficient to be measured is connected. Two microphones are mounted on the inner wall of the tube near the sample end.

A multi-channel spectrum analyzer was used to obtain the transfer function between the microphones. From the transfer function, the pressure reflection coefficient of the material is determined. From the reflection coefficient, the absorption coefficient of the sample specimens can be determined.

\section{RESULTS AND DISCUSSION}

\section{Sound absorption coefficient of beech wood by standing wave method}

The most popular method of estimation of sound absorption coefficient is the standing wave ratio method because of its simple set up and relatively accurate results. However, this method requires a single frequency operation-a traveling microphone inside the impedance tube to estimate the acoustic pressure and a means of measuring the location of minimum and maximum acoustic pressures. So, this method is relatively time and labor consuming due to these requirements. As a discrete frequency excitation and a measurement, the sound absorption coefficient represents a single value on the frequency domain.

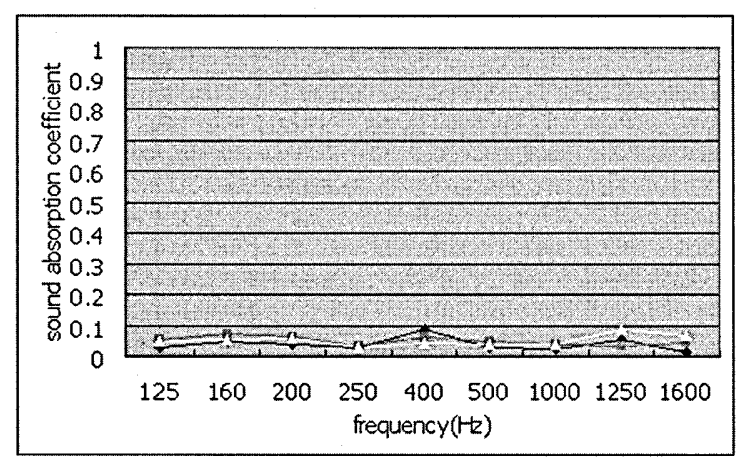

Fig. 3. Relationship between the frequency and sound absorption coefficients of beech wood by the standing wave method.
The sound absorption coefficients measured by the standing wave method are shown as in Fig. 3. As seen in the figure, the sound absorption coefficient of beech wood in cross section ranged from $3 \%$ to below $10 \%$. Although sound absorption coefficients of beech wood are relatively low, these values are higher than those of other construction materials such as concrete, steel, mortar and marble (Maekawa, 1978). Therefore, wood can be considered as a construction material for a more successful acoustic structure design.

\section{Sound absorption coefficient of beech wood mea- sured by two microphone method}

Signal-to-noise ratio in the two microphone method

In the two microphone method, accurate measurements of material absorption require that the sound field be substantially larger than the background noise inside the tube. The ISO standard recommends that the level of sound in the tube be at least $10 \mathrm{~dB}$ greater than the background noise level, but $20-30 \mathrm{~dB}$ is preferred. To achieve this low background level, the tube must be constructed of heavy materials and must be sealed properly at all openings. The air gap may cause the high sound absorption coefficients by consuming the sound energy by resonant vibration in the air gap. In this study, we sealed the openings between sample specimen and impedance tube by vacuum grease coating to prevent the air gap.

Fig. 4 shows the background noise and two microphone signals in the impedance tube at experimental condition. As seen in Fig. 4, about 60dB background noise exists in the narrow frequency range that is out of estimation frequency range and the A and B signals of two microphones attached inside impedance tube are over $30 \mathrm{~dB}$ greater than the background noise in the

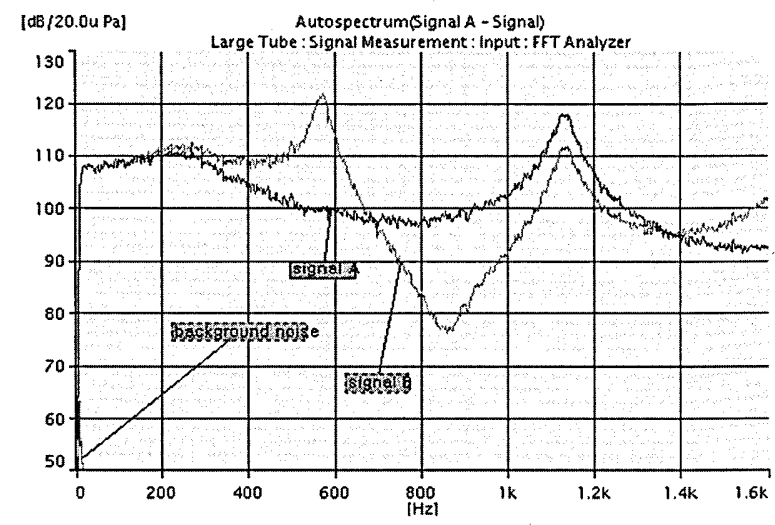

Fig. 4. The signal and background noise of two microphones in the impedance tube.

estimated frequency range.

Microphone calibration in the two microphone method

The two microphones used in the impedance tube were calibrated relatively to each other using the standard switching technique. By applying a random signal to the loudspeaker and mounting a calibration sample in 
the sample holder, the sound field inside the tube is well defined. Additionally, the microphones can be switched or interchanged without affecting the sound field. By measuring the $\mathrm{H} 1$ response in the normal and the switched position and multiplying these two response functions, the result represents a response that can be interpreted as the system error function.

The response functions shown as in Fig. 5 were used to correct the measurements on the test samples and this pro-cedure ensured that any magnitude and phase variations in the measurement were a function of the sound field, and not due to differences between the sensors.

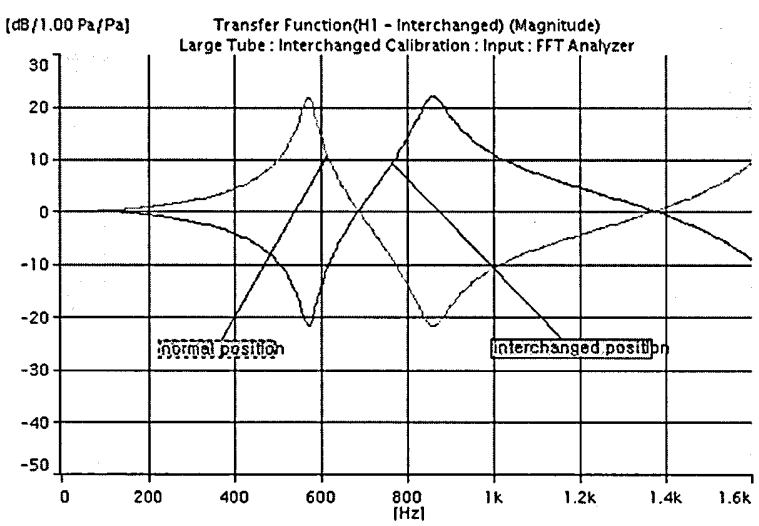

Fig. 5. The transfer functions which were measured interchanged and normal position by two microphones.

Reflection coefficient and sound absorption coefficient of beech wood

The sound absorption coefficient by two microphone method was measured for only about 60 seconds per sample specimen under a continuous frequency range. This is a considerable saving of time and labor as compared to the standard standing wave method using traveling microphone and discrete frequency excitation.

The reflection coefficients and sound absorption coefficients of beech wood are shown in Fig. 6 and Fig 7 . From Fig. 3 and Fig. 7, the sound absorption coefficients of beech wood showed about 5\%-8\% at the estimated frequency range and a good agreement was obtained from the standing wave method and two microphone method. In the frequency range of $100 \mathrm{~Hz}-200 \mathrm{~Hz}$, the value of measured by standing wave method about $2-3 \%$ higher than that of the two microphone method. On the contrary, in the frequency range of $600 \mathrm{~Hz}-800 \mathrm{~Hz}$, the measured value by the two microphone method showed a little higher than that by the standing wave method.

Consequently, there was almost no difference between the standing wave method and the two microphone transfer function method in measuring the sound absorption coefficients of beech wood at the estimated frequency range. So, it is suggested that the two microphone transfer function method be more widely used because of its simple set up, fast measurement and relatively accurate results.

Using the report of Seybert and Ross (1977) that n

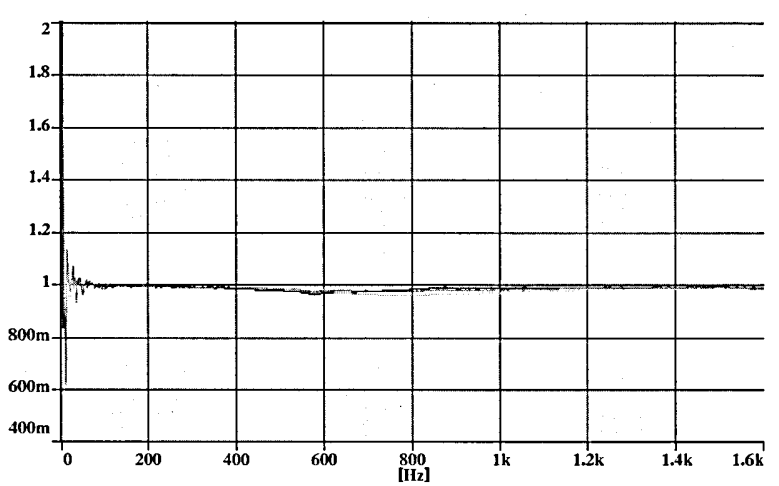

Fig. 6. Relationship between frequency and reflection coefficients of beech wood measured by two microphone method.

n

Absorption Coefficient (beech, Large)

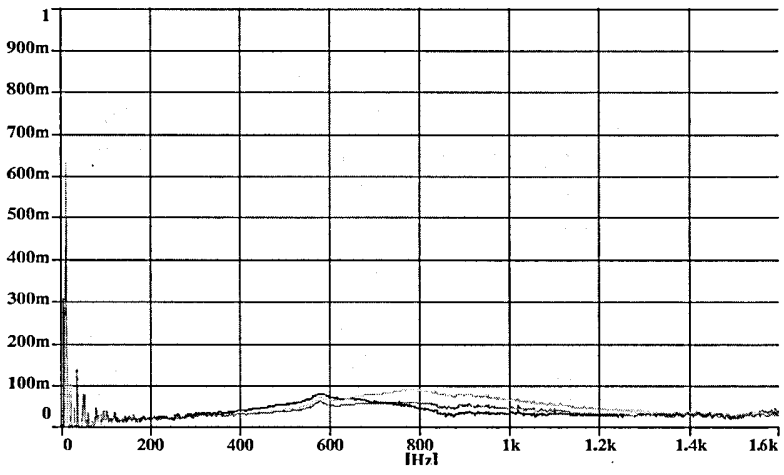

Fig. 7. Relationship between frequency and sound absorption coefficients of beech wood measured by the two microphone method.

the two microphone method is potentially useful for evaluating acoustic properties at low frequency, we measured and compared the sound absorption coefficients of beech wood by the two methods at the low frequency range of $50-1600 \mathrm{~Hz}$. But it is considered that more examinations and comparisons are needed under a high frequency range to clarify the difference between the standing wave method and two microphones method in the measurement of sound absorption coefficients.

\section{REFERENCES}

A. F. Seybert and D. F. Ross, 1977. Experimental determination of acoustic properties using a two-microphone random excitation technique. J. Acoust. Soc. Am. 61, 1362-1370

Brian F. G. Katz. 2000. Method to resolve microphone and sample location errors in the two-microphone duct measurement method. J. Acoust. Soc. Am. 108, 2231-2237

C. Suzuki, H. Yano, and H. Tachibana. 1981. A new method of measuring normal incident sound absorption characteristics of materials using acoustic tube. J. Acoust. Soc. Jpn. 2, 3: 161-167

J. Y. Chung and D. A. Blaser. 1980. Transfer function method of measuring in-duct acoustic properties. Theory. J. Acoust. Soc. Am. 68, 907-913

J. Y. Chung and D. A. Blaser. 1980. Transfer function method of measuring in-duct acoustic properties. Experiment. $J$. Acoust. Soc. Am. 68, 914-921 
Haines, James, 1989. Standing wave and two-microphone impedance tube round-robin test program. ASTM Research Report No. RR: E33-1006

ISO 10534-2. 1998. Determination of sound absorption coefficient and impedance in impedance tubes.
Maekawa J. 1978. Architectural acoustics. Kyoritsu Press: 216 (in Japanese)

R. Boonen and P. Sas 2004. Calibration of the two microphone transfer function method to measure acoustical impedance in a wide frequency range. Proceedings of ISMA 2004: 325-336 